\title{
In-vitro cytotoxic and radiosensitizing evaluation of novel 2-pyridone, isoquinoline, chromene and chromenopyridone derivatives
}

\author{
Mansour Sulaiman Al-Saida, Marwa Galal El-Gazzarb and Mostafa Mohammed Ghoraba,* \\ a Medicinal, Aromatic and Poisonous Plants Research Center, College of Pharmacy, King Saud University, Riyadh, 11451, Saudi Arabia \\ b Department of Drug Radiation Research, National Center for Radiation Research and Technology, Nasr City, Cairo, 11371, Egypt \\ *Corresponding author at: Medicinal, Aromatic and Poisonous Plants Research Center, College of Pharmacy, King Saud University, Riyadh, 11451, Saudi Arabia. \\ Tel.: +966.05.34292860; fax: +966.01.4670560. E-mail address: mmsghorab@yahoo.com (M.M. Ghorab).
}

\section{ARTICLE INFORMATION}

Received: 10 February 2012

Received in revised form: 16 March 2012

Accepted: 28 March 2012

Online: 30 June 2012

\section{KEYWORDS}

Cytotoxic

Chromene

2-Pyridone

Isoquinoline

Radiosensitizing

Chromenopyridone

\section{Introduction}

Compounds containing 2-pyridone moiety I-IV as a precursor have proven to possess several biologically properties (Scheme 1) [1-6]. In addition, different series of isoquinoline containing compounds $\mathbf{V}$ were reported to possess substantial cytotoxicity [7]. Furthermore, novel classes of chromenes bearing dithiazole VI or phenylthioamide VII moieties showed potent cytotoxicity [8], while chromenecarboxamides VIII and carboxylates proved potent anticancer activity on different cell lines and as inhibitors of tumor markers $[9,10]$. Based on the above information and as a continuation of a previous work on anticancer agents [11-16], we report the synthesis of novel 2-pyridone, isoquinoline, chromene and chromenopyridone as cytotoxic and radiosensitizing agents.

\section{Experimental}

\subsection{Instrumentation}

Chemicals were purchased from Merck, Fluka and Aldrich Chemical Companies. All yields refer to isolated products. Melting points are uncorrected and were determined on a Stuart melting point apparatus (Stuart Scientific, Redhill, UK). Elemental analysis (C, $\mathrm{H}$ and $\mathrm{N}$ ) were performed on PerkinElmer 2400 analyser (Perkin-Elmer, Norwalk, CT, USA) at The Microanalytical Laboratories of the Faculty of Science, Cairo University. All compounds were within $\pm 0.4 \%$ of the theoretical values. The IR spectra $(\mathrm{KBr})$ were measured on Shimadzu IR 110 spectrophotometer (Shimadzu, Koyoto, Japan). ${ }^{1} \mathrm{H}$ NMR spectra were obtained on a Bruker proton NMR-Avance 300 (300 MHz) (Bruker, Munich, Germany), in DMSO- $d_{6}$ as a solvent, using tetramethylsilane (TMS) as internal standard.
Mass spectra were run on HP Model MS-5988 (Hewlett Packard, Palo, Alto, California, USA). All reactions were monitored by thin layer chromatograph (TLC) using precoated aluminium sheets Silica gel Merck $60 F_{254}$ and were visualized by UV lamp (Merck, Darmstadt, Germany).

\subsection{Synthesis}

\subsubsection{2- Cyano-N-(3-ethylphenyl)acetamide (3)}

A mixture of 3-ethylaniline, 1, (1.21 g, $0.01 \mathrm{~mol})$ and ethyl cyanoacetate $(1.13 \mathrm{~g}, 0.01 \mathrm{~mol})$ was refluxed for $3 \mathrm{~h}$. The reaction mixture was concentrated and cooled. The obtained product was crystallized from ethanol to give compound 3 (Scheme 2). Yield: $88 \%$. M.p.: $86-88^{\circ} \mathrm{C}$. IR (KBr, v, cm-1): 3317 (NH), 3100 (CH. Arom.), 2960, 2870 (CH aliph.), 2260 (C三N), $1670(\mathrm{C}=0) .{ }^{1} \mathrm{H}$ NMR $\left(300 \mathrm{MHz}, \mathrm{DMSO}-d_{6}, \delta, \mathrm{ppm}\right): 1.2(\mathrm{t}, 3 \mathrm{H}$, $\left.\mathrm{CH}_{3}, J=0.66 \mathrm{~Hz}\right), 2.6\left(\mathrm{q}, 2 \mathrm{H}, \mathrm{CH}_{2}, J=0.66 \mathrm{~Hz}\right), 3.6\left(\mathrm{~s}, 2 \mathrm{H}, \mathrm{CH}_{2}\right)$, $4.2\left(\mathrm{~s}, 1 \mathrm{H}, \mathrm{NH}\right.$, exchangeable with $\left.\mathrm{D}_{2} \mathrm{O}\right), 7.0-7.7(\mathrm{~m}, 4 \mathrm{H}, \mathrm{Ar}-\mathrm{H})$. ${ }^{13} \mathrm{C}$ NMR $\left(75 \mathrm{MHz}, \mathrm{DMSO}-d_{6}, \delta, \mathrm{ppm}\right): 13.6,26.1,32.9,117.4$, $119.2,122.0,125.6,129.7,140.8,142.5,169.6$. Anal. calcd. for $\mathrm{C}_{11} \mathrm{H}_{12} \mathrm{~N}_{2} \mathrm{O}$ : C, 70.19; H, 6.38, 14.88. Found: C, 70.50; H, 6.10; N, $14.60 \%$.

\subsubsection{Ethyl 4-substituted-2-amino-5-cyano-1-(3-ethyl phenyl)-6-oxo-1,6-dihydropyridine-3-carboxylate (4a-j)}

General procedure: A mixture of compound 3 (1.88 g, 0.01 mol), appropriate aldehyde $(0.01 \mathrm{~mol})$ and ethyl cyanoacetate $(0.113 \mathrm{~g}, 0.01 \mathrm{~mol})$ in ethanol $(50 \mathrm{~mL})$ containing a catalytic amount of piperidine was refluxed for $4 \mathrm{~h}$. The obtained solid was recrystallized from dioxane to give 4a-j (Scheme 2), respectively. 
<smiles>CCc1cc(NCC2=CNc3c(Cl)ccc(Cl)c3O2)c(=O)[nH]c1C</smiles>

(I)

Pryidone L-697, 661<smiles>Cc1[nH]c(=O)c(C#N)cc1-c1ccncc1</smiles>

(II)<smiles>Nc1cc(-c2ccncc2)c[nH]c1=O</smiles>

(III)<smiles>Cc1cc(N)c(=O)n(-c2ccccc2)c1</smiles>

(IV)

Pirfenidone (PFD)<smiles>[R]NC1=C([X])C(=O)c2ccncc2C1=O</smiles>

(V)
$\mathrm{R}=\mathrm{CH}_{3}, \mathrm{CH}_{2} \mathrm{CH}_{2} \mathrm{OH}$ $\mathrm{X}=\mathrm{H}, \mathrm{Br}, \mathrm{Cl}$<smiles>[X]c1cc2occ(C3N=C(C)SS3)c(=O)c2cc1[Y2]</smiles>

(VI)<smiles>[X]c1cc2occ(C(=S)Nc3ccccc3)c(=O)c2cc1[X]</smiles>

(VII)
$\mathrm{X}_{1}=\mathrm{H}, \mathrm{F}, \mathrm{Cl}, \mathrm{CH}_{3}$ $\mathrm{X}_{2}=\mathrm{H}, \mathrm{Cl}$

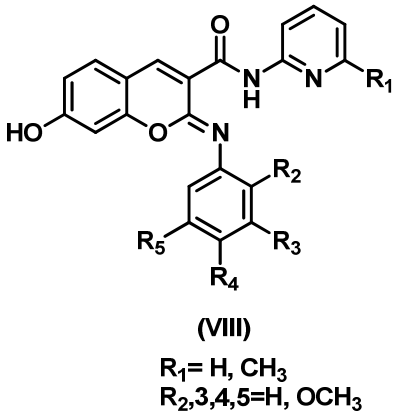

Scheme 1

Ethyl 2-amino-5-cyano-1-(3-ethylphenyl)-6-oxo-4-p-tolyl-1,6dihydro-pyridine-3-carboxylate (4a): Yield: 71\%. M.p.: 248-250 ${ }^{\circ} \mathrm{C}$. IR ( $\left.\mathrm{KBr}, v, \mathrm{~cm}^{-1}\right): 3309,3207\left(\mathrm{NH}_{2}\right), 3059$ (CH arom.), 2966, 2875 (CH aliph.), 2214 (CEN), 1676, 1687 (2C=0). ${ }^{1} \mathrm{H}$ NMR (300 MHz, DMSO-d6, $\delta, p p m): 1.1\left(\mathrm{t}, 3 \mathrm{H}, \mathrm{CH}_{3}, J=0.1 \mathrm{~Hz}\right), 1.3(\mathrm{t}$, $\left.3 \mathrm{H}, \mathrm{CH}_{3}, J=0.66 \mathrm{~Hz}\right), 1.9\left(\mathrm{~s}, 3 \mathrm{H}, \mathrm{CH}_{3}\right), 2.6\left(\mathrm{q}, 2 \mathrm{H}, \mathrm{CH}_{2}, J=0.1 \mathrm{~Hz}\right)$, $4.3\left(\mathrm{q}, 2 \mathrm{H}, \mathrm{CH}_{2}, J=0.66 \mathrm{~Hz}\right), 7.03-7.7(\mathrm{~m}, 8 \mathrm{H}, \mathrm{Ar}-\mathrm{H}), 8.2(\mathrm{~s}, 2 \mathrm{H}$, $\mathrm{NH}_{2}$, exchangeable with $\left.\mathrm{D}_{2} \mathrm{O}\right) .{ }^{13} \mathrm{C}$ NMR $\left(75 \mathrm{MHz}, \mathrm{DMSO}-d_{6}, \delta\right.$, ppm): 13.4, 15.2, 25.1, 31.9, 62.9, 86.1, 114.3, 115.0, 117.3, $119.8,122.1,125.8,127.4,130.6,131.0,133.2,136.7,140.9$, 162.7, 163.2, 164.8, 168.7. MS (m/z, \%): $401\left(\mathrm{M}^{+}, 5.1\right), 90$ (100). Anal. calcd. for $\mathrm{C}_{24} \mathrm{H}_{23} \mathrm{~N}_{3} \mathrm{O}_{3}$ : C, 71.80; $\mathrm{H}, 5.77 ; \mathrm{N}, 10.47$. Found: C, 71.40; H, 5.30; N, 10.70\%.

Ethyl 2-amino-5-cyano-1-(3-ethylphenyl)-6-oxo-4-(4methoxyphenyl)-1,6-dihydro-pyridine-3-carboxylate (4b): Yield: 89\%. M.p.: >300 ${ }^{\circ} \mathrm{C}$. IR (KBr, v, $\left.\mathrm{cm}^{-1}\right): 3309,3207\left(\mathrm{NH}_{2}\right), 3088$ ( $\left.\mathrm{CH}_{\text {arom. }}\right), 2966,2839$ (CH aliph.), $2214(\mathrm{C} \equiv \mathrm{N}), 1676,1680$ $(2 \mathrm{C}=0) .{ }^{1} \mathrm{H}$ NMR $\left(300 \mathrm{MHz}, \mathrm{DMSO}-d_{6}, \delta, \mathrm{ppm}\right): 1.1\left(\mathrm{t}, 3 \mathrm{H}, \mathrm{CH}_{3}, J\right.$ $=0.1 \mathrm{~Hz}), 1.3\left(\mathrm{t}, 3 \mathrm{H}, \mathrm{CH}_{3}, J=0.66 \mathrm{~Hz}\right), 2.6\left(\mathrm{q}, 2 \mathrm{H}, \mathrm{CH}_{2}, J=0.1 \mathrm{~Hz}\right)$, $3.5\left(\mathrm{~s}, 3 \mathrm{H}, \mathrm{OCH}_{3}\right), 4.3\left(\mathrm{q}, 2 \mathrm{H}, \mathrm{CH}_{2}, J=0.66 \mathrm{~Hz}\right), 7.0-7.7(\mathrm{~m}, 8 \mathrm{H}$, $\mathrm{Ar}-\mathrm{H}), 8.1\left(\mathrm{~s}, 2 \mathrm{H}, \mathrm{NH}_{2}\right.$, exchangeable with $\left.\mathrm{D}_{2} \mathrm{O}\right)$. MS (m/z, \%): $417\left(\mathrm{M}^{+}, 7.4\right), 167$ (100). Anal. calcd. for $\mathrm{C}_{24} \mathrm{H}_{23} \mathrm{~N}_{3} \mathrm{O}_{4}$ : C, 69.05; $\mathrm{H}$, 5.55; N, 10.07. Found: C, 69.43; H, 5.45; N, 10.34\%.

Ethyl 2-amino-5-cyano-1-(3-ethylphenyl)-6-oxo-4-(3-nitro phenyl)-1,6-dihydro-pyridine-3-carboxylate (4c): Yield: 80\%. M.p.: $145-147^{\circ} \mathrm{C}$. IR $\left(\mathrm{KBr}, v, \mathrm{~cm}^{-1}\right): 3227,3209\left(\mathrm{NH}_{2}\right), 3082(\mathrm{CH}$ arom.), 2964, 2931, 2872 (CH aliph.), $2194(\mathrm{C} \equiv \mathrm{N}), 1680,1688$ $(2 \mathrm{C}=0) .{ }^{1} \mathrm{H}$ NMR $\left(300 \mathrm{MHz}, \mathrm{DMSO}-d_{6}, \delta, \mathrm{ppm}\right): 1.05\left(\mathrm{t}, 3 \mathrm{H}, \mathrm{CH}_{3}, J\right.$ $=0.2 \mathrm{~Hz}), 1.3\left(\mathrm{t}, 3 \mathrm{H}, \mathrm{CH}_{3}, J=0.66 \mathrm{~Hz}\right), 2,6\left(\mathrm{q}, 2 \mathrm{H}, \mathrm{CH}_{2}, J=0.2 \mathrm{~Hz}\right)$, $4.3\left(\mathrm{q}, 2 \mathrm{H}, \mathrm{CH}_{2}, J=0.66 \mathrm{~Hz}\right), 7.2-7.7(\mathrm{~m}, 9 \mathrm{H}, \mathrm{Ar}-\mathrm{H}), 8.3(\mathrm{~s}, 2 \mathrm{H}$, $\mathrm{NH}_{2}$, exchangeable with $\left.\mathrm{D}_{2} \mathrm{O}\right)$. MS (m/z, \%): $432\left(\mathrm{M}^{+}, 5.7\right), 74$ (100). Anal. calcd. for $\mathrm{C}_{23} \mathrm{H}_{20} \mathrm{~N}_{4} \mathrm{O}_{5}$ : C, 63.88; H, 4.66; N, 12.96 . Found: C, 63.32; $\mathrm{H}, 4.21 ; \mathrm{N}, 13.12 \%$.

Ethyl 2-amino-5-cyano-1-(3-ethylphenyl)-6-oxo-4-(4-nitro phenyl)-1,6-dihydro-pyridine-3-carboxylate (4d): Yield: 78\%. M.p.: $140-142{ }^{\circ} \mathrm{C}$ IR (KBr, v, cm$\left.{ }^{-1}\right): 3227,3209\left(\mathrm{NH}_{2}\right), 3082(\mathrm{CH}$ arom.), 2964, 2872 (CH aliph.), $2194(\mathrm{C} \equiv \mathrm{N}), 1680,1690$ $(2 \mathrm{C}=0) .{ }^{1} \mathrm{H}$ NMR $\left(300 \mathrm{MHz}, \mathrm{DMSO}-d_{6}, \delta, \mathrm{ppm}\right): 1.05\left(\mathrm{t}, 3 \mathrm{H}, \mathrm{CH}_{3}, J\right.$ $=0.2 \mathrm{~Hz}), 1.3\left(\mathrm{t}, 3 \mathrm{H}, \mathrm{CH}_{3}, J=0.66 \mathrm{~Hz}\right), 2.6\left(\mathrm{q}, 2 \mathrm{H}, \mathrm{CH}_{2}, J=0.2 \mathrm{~Hz}\right)$, $4.3\left(\mathrm{q}, 2 \mathrm{H}, \mathrm{CH}_{2}, J=0.66 \mathrm{~Hz}\right), 7.2-7.7(\mathrm{~m}, 8 \mathrm{H}, \mathrm{Ar}-\mathrm{H}), 8.3(\mathrm{~s}, 2 \mathrm{H}$, $\mathrm{NH}_{2}$, exchangeable with $\left.\mathrm{D}_{2} \mathrm{O}\right)$. MS (m/z, \%): $432\left(\mathrm{M}^{+}, 6.9\right), 90$ (100). Anal. calcd. for $\mathrm{C}_{23} \mathrm{H}_{20} \mathrm{~N}_{4} \mathrm{O}_{5}$ : C, 63.88; H, 4.66; N, 12.96 . Found: C, 63.50; H, 4.90; N, 13.12\%.
Ethyl 2-amino-5-cyano-1-(3-ethylphenyl)-6-oxo-4-(4pipronyl)-1,6-dihydro-pyridine-3-carboxylate (4e): Yield: $81 \%$. M.p.: $160-162{ }^{\circ} \mathrm{C}$. IR $\left(\mathrm{KBr}, v, \mathrm{~cm}^{-1}\right): 3238,3209\left(\mathrm{NH}_{2}\right), 3055(\mathrm{CH}$ arom.), 2924, 2872 (CH aliph.), $2234(\mathrm{C} \equiv \mathrm{N}), 1678,1689$ $(2 \mathrm{C}=0) .{ }^{1} \mathrm{H}$ NMR $\left(300 \mathrm{MHz}, \mathrm{DMSO}-d_{6}, \delta, \mathrm{ppm}\right): 1.05\left(\mathrm{t}, 3 \mathrm{H}, \mathrm{CH}_{3}, J\right.$ $=0.2 \mathrm{~Hz}), 1.3\left(\mathrm{t}, 3 \mathrm{H}, \mathrm{CH}_{3}, J=0.66 \mathrm{~Hz}\right), 2.6\left(\mathrm{q}, 2 \mathrm{H}, \mathrm{CH}_{2}, J=0.2 \mathrm{~Hz}\right)$, $4.3\left(\mathrm{q}, 2 \mathrm{H}, \mathrm{CH}_{2}, \mathrm{~J}=0.66 \mathrm{~Hz}\right.$ ), 5.9 (s, 2H, $\mathrm{CH}_{2}$-piperonyl), 7.2-7.7 $(\mathrm{m}, 7 \mathrm{H}, \mathrm{Ar}-\mathrm{H}), 8.3\left(\mathrm{~s}, 2 \mathrm{H}, \mathrm{NH}_{2}\right.$, exchangeable with $\left.\mathrm{D}_{2} \mathrm{O}\right)$. Anal. calcd. for $\mathrm{C}_{24} \mathrm{H}_{21} \mathrm{~N}_{3} \mathrm{O}_{5}$ : C, 66.81; H, 4.91; N, 9.74. Found: C, 66.50; $\mathrm{H}, 4.90$; N, 9.51\%.

Ethyl 2-amino-5-cyano-1-(3-ethylphenyl)-6-oxo-4-(3-ethoxy4-methoxy)-1,6-dihydro-pyridine-3-carboxylate (4f): Yield: 76\%. M.p.: $167-169^{\circ} \mathrm{C}$. IR (KBr, v, cm$\left.{ }^{-1}\right): 3223,3209\left(\mathrm{NH}_{2}\right), 3055(\mathrm{CH}$ arom.), 2924, 2872 (CH aliph.), $2264(\mathrm{C} \equiv \mathrm{N}), 1679,1690$ $(2 \mathrm{C}=0) .{ }^{1} \mathrm{H}$ NMR $\left(300 \mathrm{MHz}, \mathrm{DMSO}-d_{6}, \delta, \mathrm{ppm}\right): 1.05\left(\mathrm{t}, 3 \mathrm{H}, \mathrm{CH}_{3}, J\right.$ $=0.2 \mathrm{~Hz}), 1.3\left(\mathrm{t}, 6 \mathrm{H}, 2 \mathrm{CH}_{3}, J=0.66 \mathrm{~Hz}\right), 2.6\left(\mathrm{q}, 2 \mathrm{H}, \mathrm{CH}_{2}, J=0.2\right.$ $\mathrm{Hz}), 3.5\left(\mathrm{~s}, 3 \mathrm{H}, \mathrm{OCH}_{3}\right), 4.5\left(\mathrm{q}, 4 \mathrm{H}, 2 \mathrm{CH}_{2}, J=0.66 \mathrm{~Hz}\right), 7.2-7.7(\mathrm{~m}$, $7 \mathrm{H}, \mathrm{Ar}-\mathrm{H}), 8.3$ (s, $2 \mathrm{H}, \mathrm{NH}_{2}$, exchangeable with $\left.\mathrm{D}_{2} \mathrm{O}\right)$. MS (m/z, \%): $461\left(\mathrm{M}^{+}, 10.5\right), 167$ (100). Anal. calcd. for $\mathrm{C}_{26} \mathrm{H}_{27} \mathrm{~N}_{3} \mathrm{O}_{5}$ : C, 67.66; H, 5.90; N, 9.10. Found: C, 67.32; H, 5.71; N, 9.42\%.

Ethyl 2-amino-5-cyano-1-(3-ethylphenyl)-6-oxo-4-(2,3,4trimethoxyphenyl)-1,6-dihydro-pyridine-3-carboxylate (4g): Yield: $87 \%$. M.p.: $189-190{ }^{\circ} \mathrm{C}$. IR (KBr, v, cm$\left.{ }^{-1}\right)$ : 3223, 3209 $\left(\mathrm{NH}_{2}\right), 3055$ (CH arom.), 2924, 2872 ( $\mathrm{CH}$ aliph.), $2264(\mathrm{C} \equiv \mathrm{N})$, 1679, 1687 (2C=0). ${ }^{1} \mathrm{H}$ NMR (300 MHz, DMSO- $d_{6}, \delta, \mathrm{ppm}$ ): 1.05 $\left(\mathrm{t}, 3 \mathrm{H}, \mathrm{CH}_{3}, J=0.2 \mathrm{~Hz}\right), 1.3\left(\mathrm{t}, 3 \mathrm{H}, \mathrm{CH}_{3}, J=0.66 \mathrm{~Hz}\right), 2.6(\mathrm{q}, 2 \mathrm{H}$, $\left.\mathrm{CH}_{2}, J=0.2 \mathrm{~Hz}\right), 3.8\left(\mathrm{~s}, 9 \mathrm{H}, 3 \mathrm{OCH}_{3}\right), 4.5\left(\mathrm{q}, 4 \mathrm{H}, 2 \mathrm{CH}_{2}, J=0.66 \mathrm{~Hz}\right)$, 7.2-7.7 (m, 6H, Ar-H), $8.3\left(\mathrm{~s}, 2 \mathrm{H}, \mathrm{NH}_{2}\right.$, exchangeable with $\left.\mathrm{D}_{2} \mathrm{O}\right)$. MS (m/z, \%): $573\left(\mathrm{M}^{+}, 21\right), 90$ (100). Anal. calcd. for $\mathrm{C}_{26} \mathrm{H}_{27} \mathrm{~N}_{3} \mathrm{O}_{6}: \mathrm{C}, 65.40 ; \mathrm{H}, 5.70$; N, 8.80. Found: C, 65.32; H, 5.50; N, $8.65 \%$.

Ethyl 2-amino-5-cyano-1-(3-ethylphenyl)-6-oxo-4-(2-chloro phenyl)-1,6-dihydro-pyridine-3-carboxylate (4h): Yield: $90 \%$. M.p.: 200-201 ${ }^{\circ} \mathrm{C}$. IR (KBr, v, cm-1): 3293, $3212\left(\mathrm{NH}_{2}\right), 3085(\mathrm{CH}$ arom.), 2935, 2872 (CH aliph.), $2234(\mathrm{C} \equiv \mathrm{N}), 1660,1678$ $(2 \mathrm{C}=0) .{ }^{1} \mathrm{H}$ NMR $\left(300 \mathrm{MHz}, \mathrm{DMSO}-d_{6}, \delta, \mathrm{ppm}\right): 1.05\left(\mathrm{t}, 3 \mathrm{H}, \mathrm{CH}_{3}, J\right.$ $=0.2 \mathrm{~Hz}), 1.3\left(\mathrm{t}, 3 \mathrm{H}, \mathrm{CH}_{3}, J=0.66 \mathrm{~Hz}\right), 2.6\left(\mathrm{q}, 2 \mathrm{H}, \mathrm{CH}_{2}, J=0.2 \mathrm{~Hz}\right)$, $4.5\left(\mathrm{q}, 2 \mathrm{H}, 2 \mathrm{CH}_{2}, J=0.66 \mathrm{~Hz}\right), 7.2-7.7(\mathrm{~m}, 8 \mathrm{H}, \mathrm{Ar}-\mathrm{H}), 8.3(\mathrm{~s}, 2 \mathrm{H}$, $\mathrm{NH}_{2}$, exchangeable with $\left.\mathrm{D}_{2} \mathrm{O}\right) .{ }^{13} \mathrm{C}$ NMR (75 MHz, DMSO- $d_{6}, \delta$, ppm): $13.8,15.5,31.2,63.4,86.1,116.9,117.3,118.1,119.8$, 125.6, 128.0, 128.2, 129.0, 129.6, 130.7, 133.8, 135.3, 136.1, $142.6,160.2,162.3,166.9,172.3$. Anal. calcd. for $\mathrm{C}_{23} \mathrm{H}_{20} \mathrm{ClN}_{3} \mathrm{O}_{3}$ : C, 65.48; H, 4.78; N, 9.96. Found: C, 65.32; H, 4.71; N, 9.65\%. 


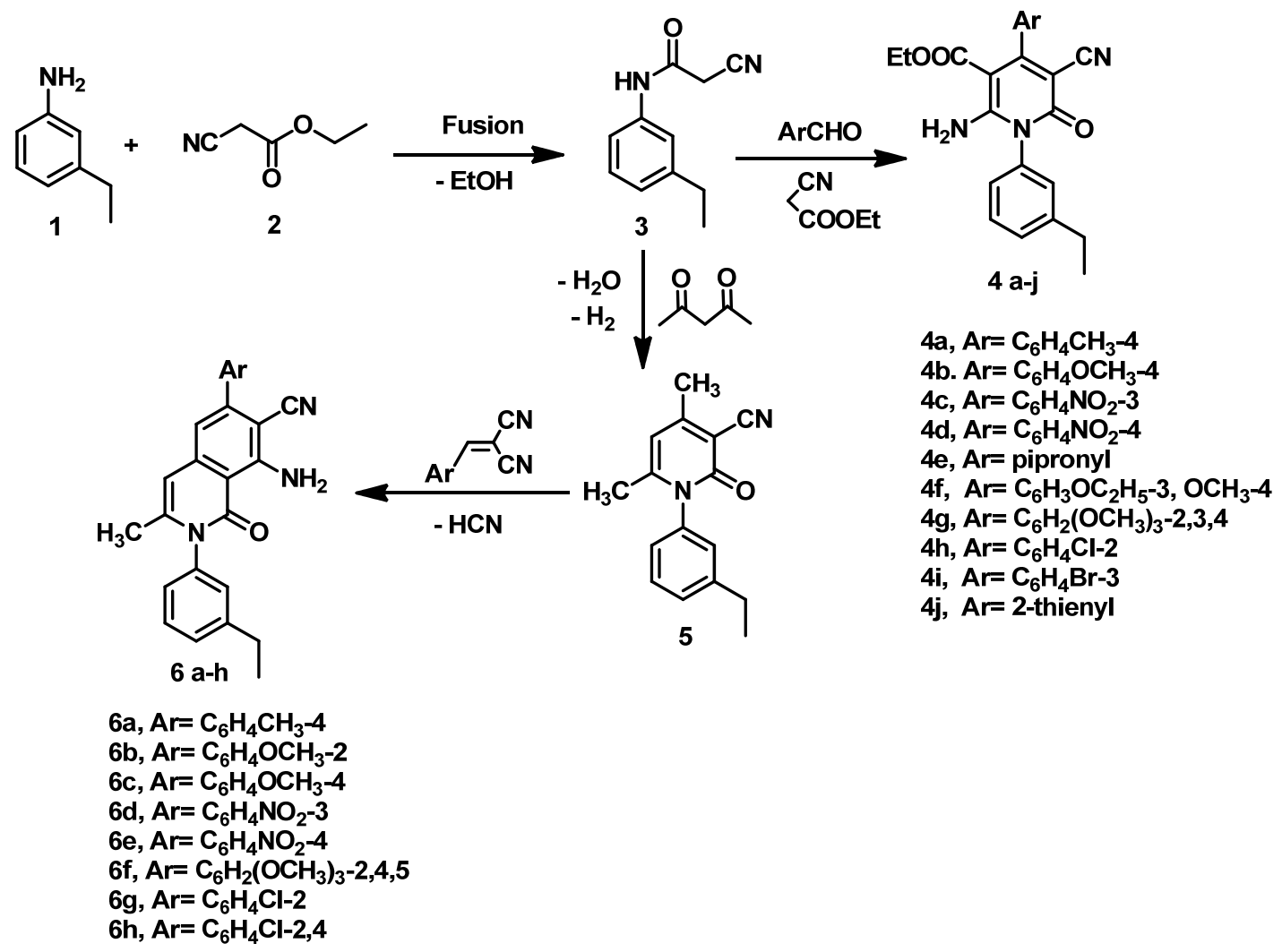

Scheme 2

Ethyl 2-amino-5-cyano-1-(3-ethylphenyl)-6-oxo-4-(3-bromo phenyl)-1,6-dihydro-pyridine-3-carboxylate (4i): Yield: $62 \%$. M.p.: $96-98{ }^{\circ} \mathrm{C}$. IR $\left(\mathrm{KBr}, v, \mathrm{~cm}^{-1}\right): 3334,3246\left(\mathrm{NH}_{2}\right), 3086(\mathrm{CH}$ arom.), 2981, 2829 (CH aliph.), $2212(\mathrm{C} \equiv \mathrm{N}), 1649,1966$ $(2 \mathrm{C}=0) .{ }^{1} \mathrm{H}$ NMR $\left(300 \mathrm{MHz}\right.$, DMSO- $\left.d_{6}, \delta, \mathrm{ppm}\right): 1.2\left(\mathrm{t}, 3 \mathrm{H}, \mathrm{CH}_{3}, J\right.$ $=0.66 \mathrm{~Hz}), 1.9\left(\mathrm{t}, 3 \mathrm{H}, \mathrm{CH}_{3}, J=0.66 \mathrm{~Hz}\right), 2.6\left(\mathrm{q}, 2 \mathrm{H}, \mathrm{CH}_{2}, J=6.66\right.$ $\mathrm{Hz}), 4.5\left(\mathrm{q}, 2 \mathrm{H}, \mathrm{CH}_{2}, J=0.66 \mathrm{~Hz}\right), 7.1-7.9(\mathrm{~m}, 8 \mathrm{H}, \mathrm{Ar}-\mathrm{H}), 8.6(\mathrm{~s}$, $2 \mathrm{H}, \mathrm{NH}_{2}$, exchangeable with $\left.\mathrm{D}_{2} \mathrm{O}\right)$. MS $(\mathrm{m} / \mathrm{z}, \%): 466\left(\mathrm{M}^{+}, 15.8\right)$, 90 (100). Anal. calcd. for $\mathrm{C}_{23} \mathrm{H}_{20} \mathrm{BrN}_{3} \mathrm{O}_{3}$ : C, 59.24; $\mathrm{H}, 4.32$; N, 9.01. Found: C, 59.50; H, 4.20; N, 9.20\%.

Ethyl 2-amino-5-cyano-1-(3-ethylphenyl)-6-oxo-4-(thiophen2-yl)-1,6-dihydro-pyridine-3-carboxylate (4j): Yield: 71\%. M.p.: 105-107 ${ }^{\circ} \mathrm{C}$. IR $\left(\mathrm{KBr}, v, \mathrm{~cm}^{-1}\right): 3325,3209\left(\mathrm{NH}_{2}\right), 3100(\mathrm{CH}$ arom.), 2931, 2872 (CH aliph.), $2210(\mathrm{C} \equiv \mathrm{N}), 1658$ (C=0). ${ }^{1} \mathrm{H}$ NMR (300 MHz, DMSO- $\left.d_{6}, \delta, \mathrm{ppm}\right): 1.2\left(\mathrm{t}, 3 \mathrm{H}, \mathrm{CH}_{3}, J=0.66 \mathrm{~Hz}\right)$, $1.7\left(\mathrm{t}, 3 \mathrm{H}, \mathrm{CH}_{3}, J=0.66 \mathrm{~Hz}\right), 2.6\left(\mathrm{q}, 2 \mathrm{H}, \mathrm{CH}_{2}, J=6.66 \mathrm{~Hz}\right), 4.7(\mathrm{q}$, $\left.2 \mathrm{H}, \mathrm{CH}_{2}, J=0.66 \mathrm{~Hz}\right), 7.2-7.7(\mathrm{~m}, 4 \mathrm{H}, \mathrm{Ar}-\mathrm{H}), 7.5-8.4(\mathrm{~m}, 3 \mathrm{H}, 3 \mathrm{CH}$ thiophene), $8.7\left(\mathrm{~s}, 2 \mathrm{H}, \mathrm{NH}_{2}\right.$, exchangeable with $\left.\mathrm{D}_{2} \mathrm{O}\right)$. Anal. calcd. for $\mathrm{C}_{21} \mathrm{H}_{19} \mathrm{~N}_{3} \mathrm{O}_{3} \mathrm{~S}: \mathrm{C}, 64.10 ; \mathrm{H}, 4.87 ; \mathrm{N}, 10.68$. Found: $\mathrm{C}, 64.50 ; \mathrm{H}$, $4.70 ; \mathrm{N}, 10.40 \%$.

\subsubsection{1-(3-Ethylphenyl)-4,6-dimethyl-2-oxo-1,2-dihydro pyridine-3-carbonitrile (5)}

Equimolar amounts of compound 3 (1.88 g, $0.01 \mathrm{~mol}$ ) and acetylacetone $(1.00 \mathrm{~g}, 0.01 \mathrm{~mol})$ were refluxed in ethanol (50 $\mathrm{mL})$ containing piperidine $(0.5 \mathrm{~mL})$ for $5 \mathrm{~h}$. The reaction mixture was triturated with ethanol and the solid obtained was recrystallized from dioxane to give compound 5 (Scheme 2). Yield: $86 \%$. M.p.: $198-200{ }^{\circ} \mathrm{C}$. IR $\left(\mathrm{KBr}, \mathrm{v}, \mathrm{cm}^{-1}\right): 3100(\mathrm{CH}$ arom.), 2931, 2872 (CH aliph.), $2210(\mathrm{C} \equiv \mathrm{N}), 1660(\mathrm{C}=0) .{ }^{1} \mathrm{H}$ NMR (300 MHz, DMSO- $\left.d_{6}, \delta, \mathrm{ppm}\right): 1.2\left(\mathrm{t}, 3 \mathrm{H}, \mathrm{CH}_{3}, J=0.66 \mathrm{~Hz}\right)$, $1.5\left(2 \mathrm{~s}, 6 \mathrm{H}, 2 \mathrm{CH}_{3}\right), 2.6\left(\mathrm{q}, 2 \mathrm{H}, \mathrm{CH}_{2}, J=0.66 \mathrm{~Hz}\right), 5.6(\mathrm{~s}, 1 \mathrm{H}, \mathrm{CH}-$ pyridine), 7.2-7.7 (m, 4H, Ar-H). Anal. calcd. for $\mathrm{C}_{16} \mathrm{H}_{16} \mathrm{~N}_{2} \mathrm{O}$ : C, 76.16; H, 6.39; N, 11.10. Found: C, 76.50; H, 6.70; N, 11.40\%.

2.2.4. 6-Substituted-8-amino-2-(3-ethylphenyl)-3-methyl-1oxo-1,2-dihydro- isoquinoline-7-carbonitrile (6a-h)

General procedure: A mixture of compound 5 (1.5 g, 0.01 mol), benzylidine-malononitrile $(0.01 \mathrm{~mol})$ in ethanol $(50 \mathrm{~mL})$ containing $(0.5 \mathrm{~mL})$ piperidine was refluxed for $6 \mathrm{~h}$. The reaction mixture was cooled and poured onto ice water acidified with dil. HCl. The solid obtained was recrystallized from dioxane to give compounds $\mathbf{6 a - h}$ (Scheme 2).

8-Amino-2-(3-ethylphenyl)-3-methyl-1-oxo-6-p-tolyl-1,2dihydro- isoquinoline-7-carbonitrile (6a): Yield: 90\%. M.p.: 108$109{ }^{\circ} \mathrm{C}$. IR ( $\left.\mathrm{KBr}, v, \mathrm{~cm}^{-1}\right): 3325,3209\left(\mathrm{NH}_{2}\right), 3080$ ( $\mathrm{CH}$ arom.), 2931, 2872 (CH aliph.), $2210(\mathrm{C} \equiv \mathrm{N}), 1658(\mathrm{C}=0) .{ }^{1} \mathrm{H}$ NMR $(300$ MHz, DMSO- $\left.d_{6}, \delta, \mathrm{ppm}\right): 1.2\left(\mathrm{t}, 3 \mathrm{H}, \mathrm{CH}_{3}, J=0.66 \mathrm{~Hz}\right), 1.7(\mathrm{~s}, 3 \mathrm{H}$, $\left.\mathrm{CH}_{3}\right), 2.6\left(\mathrm{q}, 2 \mathrm{H}, \mathrm{CH}_{2}, J=0.66 \mathrm{~Hz}\right), 5.7(\mathrm{~s}, 1 \mathrm{H}, \mathrm{CH}$-pyridine), 6.9$7.5(\mathrm{~m}, 8 \mathrm{H}, \mathrm{Ar}-\mathrm{H}), 8.7\left(\mathrm{~s}, 2 \mathrm{H}, \mathrm{NH}_{2}\right.$, exchangeable with $\left.\mathrm{D}_{2} \mathrm{O}\right) .{ }^{13} \mathrm{C}$ NMR (75 MHz, DMSO- $\left.d_{6}, \delta, \mathrm{ppm}\right): 12.9,21.3,26.4,33.8,96.0$, $100.3,116.8,118.2,118.9,119.8,121.7,124.5,126.8,127.6$, $130.9,133.4,134.8,139.0,140.9,142.4,144.6,147.8,151.3$, 158.4. Anal. calcd. for $\mathrm{C}_{26} \mathrm{H}_{23} \mathrm{~N}_{3} \mathrm{O}: \mathrm{C}, 79.36 ; \mathrm{H}, 5.89 ; \mathrm{N}, 10.68$. Found: C, 79.50; H, 5.70; N, 10.40\%.

Amino-2-(3-ethylphenyl)-3-methyl-1-oxo-6-(2-methoxy phenyl)-1,2-dihydro- isoquinoline-7-carbonitrile (6b): Yield: 92\%. M.p.: $114-116{ }^{\circ} \mathrm{C}$. IR (KBr, v, cm-1): 3325, $3209\left(\mathrm{NH}_{2}\right)$, 3080 (CH arom.), 2931, 2872 ( $\mathrm{CH}$ aliph.), $2212(\mathrm{C} \equiv \mathrm{N}), 1658$ $(\mathrm{C}=0) .{ }^{1} \mathrm{H}$ NMR $\left(300 \mathrm{MHz}, \mathrm{DMSO}-d_{6}, \delta, \mathrm{ppm}\right): 1.2\left(\mathrm{t}, 3 \mathrm{H}, \mathrm{CH}_{3}, J=\right.$ $0.66 \mathrm{~Hz}$ ), $2.6\left(\mathrm{q}, 2 \mathrm{H}, \mathrm{CH}_{2}, J=0.66 \mathrm{~Hz}\right), 3.8\left(\mathrm{~s}, 3 \mathrm{H}, \mathrm{OCH}_{3}\right), 5.7(\mathrm{~s}$, $1 \mathrm{H}$, CH-pyridine), 6.9-7.9 (m, 8H, Ar-H), $8.7\left(\mathrm{~s}, 2 \mathrm{H}, \mathrm{NH}_{2}\right.$, exchangeable with $\left.\mathrm{D}_{2} \mathrm{O}\right)$. MS $(\mathrm{m} / \mathrm{z}, \%): 409\left(\mathrm{M}^{+}, 5.12\right), 105$ (100). Anal. calcd. for $\mathrm{C}_{26} \mathrm{H}_{23} \mathrm{~N}_{3} \mathrm{O}_{2}$ : C, 76.26; $\mathrm{H}, 5.66$; N, 10.26 . Found: C, 76.50; H, 5.70; N, 10.50\%. 


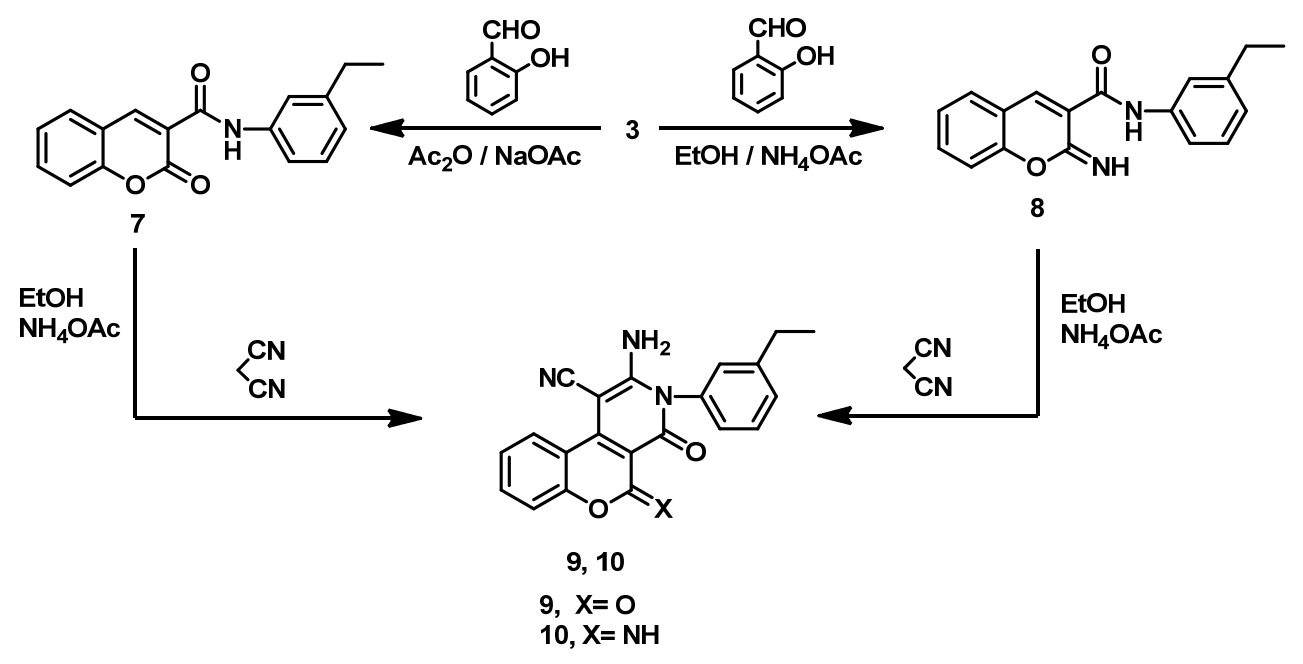

Scheme 3

8-Amino-2-(3-ethylphenyl)-3-methyl-1-oxo-6-(4-methoxy phenyl)-1,2-dihydro-isoquinoline-7-carbonitrile (6c): Yield: $97 \%$. M.p.: $122-124^{\circ} \mathrm{C}$. IR $\left(\mathrm{KBr}, v, \mathrm{~cm}^{-1}\right): 3325,3209\left(\mathrm{NH}_{2}\right), 3080(\mathrm{CH}$ arom.), 2931, 2860 (CH aliph.), $2200(\mathrm{C} \equiv \mathrm{N}), 1658$ (C=0). ${ }^{1} \mathrm{H}$ NMR (300 MHz, DMSO- $\left.d_{6}, \delta, \mathrm{ppm}\right): 1.2\left(\mathrm{t}, 3 \mathrm{H}, \mathrm{CH}_{3}, J=0.66 \mathrm{~Hz}\right)$, $2.6\left(\mathrm{q}, 2 \mathrm{H}, \mathrm{CH}_{2}, J=0.66 \mathrm{~Hz}\right), 3.7\left(\mathrm{~s}, 3 \mathrm{H}, \mathrm{OCH}_{3}\right), 5.7(\mathrm{~s}, 1 \mathrm{H}, \mathrm{CH}-$ pyridine), 6.9-7.8 (m, $8 \mathrm{H}, \mathrm{Ar}-\mathrm{H}), 8.7\left(\mathrm{~s}, 2 \mathrm{H}, \mathrm{NH}_{2}\right.$, exchangeable with $\left.\mathrm{D}_{2} \mathrm{O}\right)$. MS $(\mathrm{m} / \mathrm{z}, \%): 409\left(\mathrm{M}^{+}, 12.1\right), 90(100)$. Anal. calcd. for $\mathrm{C}_{26} \mathrm{H}_{23} \mathrm{~N}_{3} \mathrm{O}_{2}$ : C, 76.26; $\mathrm{H}, 5.66 ; \mathrm{N}, 10.26$. Found: C, 76.60; $\mathrm{H}$, $5.70 ; \mathrm{N}, 10.10 \%$.

8-Amino-2-(3-ethylphenyl)-3-methyl-1-oxo-6-(3-nitro phenyl)-1,2-dihydro-isoquinoline-7-carbonitrile (6d): Yield: 89\%. M.p.: 98-100 ${ }^{\circ} \mathrm{C}$. IR (KBr, v, cm-1): 3325, $3220\left(\mathrm{NH}_{2}\right), 3080$ (CH arom.), 2931, 2850(CH aliph.), 2208 (CEN), 1658 (C=0). ${ }^{1} \mathrm{H}$ NMR (300 MHz, DMSO- $\left.d_{6}, \delta, p p m\right): 1.2\left(\mathrm{t}, 3 \mathrm{H}, \mathrm{CH}_{3}, J=0.66 \mathrm{~Hz}\right)$, $2.6\left(\mathrm{q}, 2 \mathrm{H}, \mathrm{CH}_{2}, J=0.66 \mathrm{~Hz}\right), 5.7$ (s, 1H, CH-pyridine), 6.9-7.5 (m, $8 \mathrm{H}, \mathrm{Ar}-\mathrm{H}), 8.7\left(\mathrm{~s}, 2 \mathrm{H}, \mathrm{NH}_{2}\right.$, exchangeable with $\left.\mathrm{D}_{2} \mathrm{O}\right)$. $\mathrm{MS}(\mathrm{m} / \mathrm{z}$, \%): $424\left(\mathrm{M}^{+}, 18.2\right), 90$ (100). Anal. calcd. for $\mathrm{C}_{25} \mathrm{H}_{20} \mathrm{~N}_{4} \mathrm{O}_{3}$ : C, 70.74; H, 4.75; N, 13.20. Found: C, 70.50; H, 4.70; N, 13.40 .

8-Amino-2-(3-ethylphenyl)-3-methyl-1-oxo-6-(4-nitro phenyl)-1,2-dihydro-isoquinoline-7-carbonitrile (6e): Yield: 85\%. M.p.: 106-108 ${ }^{\circ} \mathrm{C}$. IR (KBr, v, $\left.\mathrm{cm}^{-1}\right)$ : 3340, $3218\left(\mathrm{NH}_{2}\right)$,

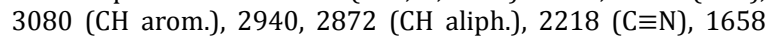
$(\mathrm{C}=0) .{ }^{1} \mathrm{H}$ NMR $\left(300 \mathrm{MHz}, \mathrm{DMSO}-d_{6}, \delta, \mathrm{ppm}\right): 1.2\left(\mathrm{t}, 3 \mathrm{H}, \mathrm{CH}_{3}, J=\right.$ $0.66 \mathrm{~Hz}), 2.6\left(\mathrm{q}, 2 \mathrm{H}, \mathrm{CH}_{2}, J=0.66 \mathrm{~Hz}\right), 5.7(\mathrm{~s}, 1 \mathrm{H}, \mathrm{CH}$-pyridine), 6.9-7.5 (m, 8H, Ar-H), $8.7\left(\mathrm{~s}, 2 \mathrm{H}, \mathrm{NH}_{2}\right.$, exchangeable with $\left.\mathrm{D}_{2} \mathrm{O}\right)$. MS (m/z, \%): $424\left(\mathrm{M}^{+}, 20.3\right), 141$ (100). Anal. calcd. for $\mathrm{C}_{25} \mathrm{H}_{20} \mathrm{~N}_{4} \mathrm{O}_{3}$ : C, 70.74; $\mathrm{H}, 4.75 ; \mathrm{N}, 13.20$. Found: $\mathrm{C}, 70.50 ; \mathrm{H}, 4.50$; $\mathrm{N}, 13.60 \%$.

8-Amino-2-(3-ethylphenyl)-3-methyl-1-oxo-6-(2, 4, 5-trimethoxyphenyl)-1,2-dihydro- isoquinoline-7-carbonitrile (6f): Yield: 79\%. M.p.: 117-119 ${ }^{\circ} \mathrm{C}$. IR (KBr, v, $\left.\mathrm{cm}^{-1}\right)$ : 3364, $3209\left(\mathrm{NH}_{2}\right)$, 3080 (CH arom.), 2931, 2836 ( $\mathrm{CH}$ aliph.), 2213 (C三N), 1658 $(\mathrm{C}=0) .{ }^{1} \mathrm{H}$ NMR $\left(300 \mathrm{MHz}\right.$, DMSO- $\left.d_{6}, \delta, \mathrm{ppm}\right): 1.2\left(\mathrm{t}, 3 \mathrm{H}, \mathrm{CH}_{3}, J=\right.$ $0.66 \mathrm{~Hz}), 2.6\left(\mathrm{q}, 2 \mathrm{H}, \mathrm{CH}_{2}, J=0.66 \mathrm{~Hz}\right), 3.7\left(3 \mathrm{~S}, 9 \mathrm{H}, 3 \mathrm{CH}_{3}\right), 5.7(\mathrm{~s}$, $1 \mathrm{H}$, CH-pyridine), 6.9-7.6 (m, 6H, Ar-H), $8.7\left(\mathrm{~s}, 2 \mathrm{H}, \mathrm{NH}_{2}\right.$, exchangeable with $\left.\mathrm{D}_{2} \mathrm{O}\right)$. $\mathrm{MS}(\mathrm{m} / \mathrm{z}, \%): 469\left(\mathrm{M}^{+}, 24.1\right), 90(100)$. Anal. calcd. for $\mathrm{C}_{28} \mathrm{H}_{27} \mathrm{~N}_{3} \mathrm{O}_{4}$ : C, 71.62; H, 5.80; N, 8.95. Found: C, 71.30; H, 5.40; N, 9.10\%.

8-Amino-2-(3-ethylphenyl)-3-methyl-1-oxo-6-(2-chlorophenyl)1,2-dihydro- isoquinoline-7-carbonitrile (6g): Yield: $80 \%$. M.p.: 107-110 ${ }^{\circ} \mathrm{C}$. IR $\left(\mathrm{KBr}, v, \mathrm{~cm}^{-1}\right): 3370,3230\left(\mathrm{NH}_{2}\right), 3080(\mathrm{CH}$ arom.), 2920, 2860 (CH aliph.), 2209 (C三N), 1658 (C=0). ${ }^{1} \mathrm{H}$ NMR (300 MHz, DMSO- $\left.d_{6}, \delta, p p m\right): 1.2\left(\mathrm{t}, 3 \mathrm{H}, \mathrm{CH}_{3}, J=0.66 \mathrm{~Hz}\right)$, $2.6\left(\mathrm{q}, 2 \mathrm{H}, \mathrm{CH}_{2}, \mathrm{~J}=0.66 \mathrm{~Hz}\right), 5.7$ (s, 1H, CH-pyridine), 7.1-7.7 (m, $8 \mathrm{H}, \mathrm{Ar}-\mathrm{H}), 8.7\left(\mathrm{~s}, 2 \mathrm{H}, \mathrm{NH}_{2}\right.$, exchangeable with $\left.\mathrm{D}_{2} \mathrm{O}\right)$. $\mathrm{MS}(\mathrm{m} / \mathrm{z}$,
\%): $413\left(\mathrm{M}^{+}, 35\right), 105$ (100). Anal. calcd. for $\mathrm{C}_{25} \mathrm{H}_{20} \mathrm{ClN}_{3} \mathrm{O}$ : C, $72.55 ; \mathrm{H}, 4.87 ; \mathrm{N}, 10.15$. Found: $\mathrm{C}, 72.70 ; \mathrm{H}, 4.70 ; \mathrm{N}, 10.50 \%$. 8-Amino-2-(3-ethylphenyl)-3-methyl-1-oxo-6-(2,4-dichloro phenyl)-1,2-dihydro- isoquinoline-7-carbonitrile (6h): Yield: 87\%. M.p.: $97-99^{\circ} \mathrm{C}$. IR (KBr, v, cm-1): 3325, $3209\left(\mathrm{NH}_{2}\right), 3080$ (CH arom.), 2930, 2856(CH aliph.), $2198(\mathrm{C} \equiv \mathrm{N}), 1658(\mathrm{C}=0) .{ }^{1} \mathrm{H}$ NMR (300 MHz, DMSO- $\left.d_{6}, \delta, p p m\right): 1.2\left(\mathrm{t}, 3 \mathrm{H}, \mathrm{CH}_{3}, J=0.66 \mathrm{~Hz}\right)$, $2.6\left(\mathrm{q}, 2 \mathrm{H}, \mathrm{CH}_{2}, J=0.66 \mathrm{~Hz}\right), 5.7$ (s, 1H, CH-pyridine), 6.9-7.9 (m, $7 \mathrm{H}, \mathrm{Ar}-\mathrm{H}), 8.7$ (s, $2 \mathrm{H}, \mathrm{NH}_{2}$, exchangeable with $\left.\mathrm{D}_{2} \mathrm{O}\right) . \mathrm{MS}(\mathrm{m} / \mathrm{z}$, \%): $448\left(\mathrm{M}^{+}, 5.9\right), 141(100)$. Anal. calcd. for $\mathrm{C}_{25} \mathrm{H}_{20} \mathrm{Cl}_{2} \mathrm{~N}_{3} \mathrm{O}$ : C, $66.97 ; \mathrm{H}, 4.27$; N, 9.37. Found: C, 66.60; H, 4.60; N, 9.60\%.

\subsubsection{N-(3-ethylphenyl)-2-oxo-2H-chromene-3-carboxamide} (7)

To a solution of compound $3(1.88 \mathrm{~g}, 0.01 \mathrm{~mol})$ in acetic anhydride $(20 \mathrm{~mL})$, salicyladehyde $(1.22 \mathrm{~g}, 0.01 \mathrm{~mol})$ and fused sodium acetate $(0.8 \mathrm{~g}, 0.01 \mathrm{mo})$ was added. The reaction mixture was refluxed for $2 \mathrm{~h}$, cooled and the solid obtained was crystallized from ethanol to give compound 7 (Scheme 3). Yield: $69 \%$. M.p.: $117-119^{\circ} \mathrm{C}$. IR $\left(\mathrm{KBr}, v, \mathrm{~cm}^{-1}\right): 3417(\mathrm{NH}), 1766$ $(2 \mathrm{C}=0) .{ }^{1} \mathrm{H}$ NMR $\left(300 \mathrm{MHz}, \mathrm{DMSO}-d_{6}, \delta, \mathrm{ppm}\right): 1.3\left(\mathrm{t}, 3 \mathrm{H}, \mathrm{CH}_{3}, J\right.$ $=0.2 \mathrm{~Hz}) 2.6\left(\mathrm{q}, 2 \mathrm{H}, \mathrm{CH}_{2}, J=0.2 \mathrm{~Hz}\right), 7.3-8.0(\mathrm{~m}, 8 \mathrm{H}, \mathrm{Ar}-\mathrm{H}), 8.35$ (s, $1 \mathrm{H}, \mathrm{CH}), 8.42\left(\mathrm{~s}, 1 \mathrm{H}, \mathrm{NH}\right.$, exchangeable with $\left.\mathrm{D}_{2} \mathrm{O}\right) .{ }^{13} \mathrm{C}$ NMR (75 MHz, DMSO- $d_{6}, \delta, \mathrm{ppm}$ ): 14.1, 30.2, 113.6, 117.5, 119.8, $122.7,124.2,125.6,127.0,127.9,129.6,130.2,133.5,136.1$, 140.2, 153.6, 161.2, 164.3. Anal. calcd. for $\mathrm{C}_{18} \mathrm{H}_{15} \mathrm{NO}_{3}$ : C, 73.71; H, 5.15; N, 4.78. Found: C, 73.60; H, 5.70; N, 4.50\%.

\subsection{6. $\mathrm{N}$-(3-ethylphenyl)-2-imino-2H-chromene-3- carboxamide (8)}

A mixture of compound 3 (1.88 g, $0.01 \mathrm{~mol})$, salicyladehyde $(1.22 \mathrm{~g}, 0.01 \mathrm{~mol})$ and anhydrous ammonium acetate $(1.15 \mathrm{~g}$, $0.15 \mathrm{~mol})$ in ethanol $(20 \mathrm{~mL})$ was refluxed for $2 \mathrm{~h}$. The solid obtained was recrystallized from ethanol to give compound 8 (Scheme 3). Yield: $59 \%$. M.p.: $>300{ }^{\circ} \mathrm{C}$. IR $\left(\mathrm{KBr}, v, \mathrm{~cm}^{-1}\right): 3344$, $3166(2 \mathrm{NH}), 1720(\mathrm{C}=0), 1570(\mathrm{C}=\mathrm{N}) .{ }^{1} \mathrm{H}$ NMR $(300 \mathrm{MHz}$, DMSO- $\left.d_{6}, \delta, \mathrm{ppm}\right): 1.1\left(\mathrm{t}, 3 \mathrm{H}, \mathrm{CH}_{3}, J=0.2 \mathrm{~Hz}\right) 2.7\left(\mathrm{q}, 2 \mathrm{H}, \mathrm{CH}_{2}, J=\right.$ $0.2 \mathrm{~Hz}$ ), 6.9-8.3 (m, 8H, Ar-H), 8.7 (s, 1H, CH-4), 9.5 (s, 1H, NH imino, exchangeable with $\left.\mathrm{D}_{2} \mathrm{O}\right), 12.5(\mathrm{~s}, 1 \mathrm{H}, \mathrm{NHCO}$, exchangeable with $\left.\mathrm{D}_{2} \mathrm{O}\right) .{ }^{13} \mathrm{C}$ NMR $\left(75 \mathrm{MHz}\right.$, DMSO- $\left.d_{6}, \delta, \mathrm{ppm}\right)$ : 13.4, 31.2, 114.6, 115.8, 117.1, 119.8, 122.6, 123.3, 124.7, 126.2, 127.5, 128.7, 130.6, 133.8, 137.1, 152.9, 162.7, 171.3. Anal. calcd. for $\mathrm{C}_{18} \mathrm{H}_{16} \mathrm{~N}_{2} \mathrm{O}_{2}: \mathrm{C}, 73.95 ; \mathrm{H}, 5.52, \mathrm{~N}, 9.58$. Found: C, 73.60; H, 5.20; N, 9.30\%. 
2.2.7. 2-Amino-3-(3-ethylphenyl)-4,5-dioxo-4,5-dihydro-3Hchromeno(3,4-c)pyridine-1-carbonitrile (9) and 2-amino-3(3-ethylphenyl)-5-imino-4-oxo-4,5-dihydro-3H-chromeno (3,4-c)pyridine-1-carbonitrile (10)

Equimolar amounts of compounds $\mathbf{7}$ or $\mathbf{8}$, malononitrile $(0.66 \mathrm{~g}, 0.01 \mathrm{~mol})$ anhydrous ammonium acetate $(1.115 \mathrm{~g}, 0.01$ mol) in ethanol were refluxed for $4 \mathrm{~h}$. The solid obtained by filtration was recrystallized from dioxane to give compound 9 and 10, (Scheme 3 ) respectively.

2-Amino-3-(3-ethylphenyl)-4,5-dioxo-4,5-dihydro-3Hchromeno(3,4-c)pyridine-1-carbonitrile (9): Yield: 61\%. M.p.: $>300{ }^{\circ} \mathrm{C}$. IR (KBr, $v, \mathrm{~cm}^{-1}$ ): 3090 (CH arom.), 2976, 2865 (CH aliph.), 1684, $1654(2 \mathrm{C}=0)$. ${ }^{1} \mathrm{H}$ NMR (300 MHz, DMSO- $d_{6}, \delta$, ppm): $1.2\left(\mathrm{t}, 3 \mathrm{H}, \mathrm{CH}_{3}, J=0.66 \mathrm{~Hz}\right), 2.6\left(\mathrm{q}, 2 \mathrm{H}, \mathrm{CH}_{2}, J=0.66 \mathrm{~Hz}\right)$, 6.9-7.5 (m, 8H, Ar-H). ${ }^{13} \mathrm{C}$ NMR (75 MHz, DMSO- $d_{6}, \delta$, ppm): $15.8,34.3,73.9,116.5,117.9,118.0,119.2,122.6,125.3,126.1$, $127.0,127.8,128.9,129.3,135.6,141.2,153.6,156.4,158.8$, 161.4, 167.5. MS $(\mathrm{m} / \mathrm{z}, \%): 357\left(\mathrm{M}^{+}, 17.8\right), 76(100)$. Anal. calcd. for $\mathrm{C}_{21} \mathrm{H}_{15} \mathrm{~N}_{3} \mathrm{O}_{3}$ : C, 70.8; $\mathrm{H}, 4.23$;, 11.76 . Found: $\mathrm{C}, 75.40 ; \mathrm{H}$, $4.60 ; \mathrm{N}, 4.10$.

2-Amino-3-(3-ethylphenyl)-5-imino-4-oxo-4,5-dihydro-3Hchromeno[3,4-c]pyridine-1-carbonitrile (10): Yield: 58\%. M.p.: $>300{ }^{\circ} \mathrm{C}$. IR $\left(\mathrm{KBr}, v, \mathrm{~cm}^{-1}\right): 3312,3256,3216\left(\mathrm{NH}, \mathrm{NH}_{2}\right)$, 3070 (CH arom.), 2925, 2853 (CH aliph.), 1690(C=0). ${ }^{1} \mathrm{H}$ NMR ( $300 \mathrm{MHz}$, DMSO- $d_{6}, \delta, \mathrm{ppm}$ ): $1.2\left[\mathrm{t}, 3 \mathrm{H}, \mathrm{CH}_{3}, J=0.66 \mathrm{~Hz}\right.$ ), $2.6(\mathrm{q}$, $\left.2 \mathrm{H}, \mathrm{CH}_{2}, J=0.66 \mathrm{~Hz}\right), 6.9-7.8(\mathrm{~m}, 8 \mathrm{H}, \mathrm{Ar}-\mathrm{H}), 8.7(\mathrm{~s}, 1 \mathrm{H}, \mathrm{NH}$, exchangeable with $\left.\mathrm{D}_{2} \mathrm{O}\right), 10.1\left(\mathrm{~s}, 2 \mathrm{H}, \mathrm{NH}_{2}\right.$, exchangeable with $\left.\mathrm{D}_{2} \mathrm{O}\right)$. MS ( $\left.\mathrm{m} / \mathrm{z}, \%\right): 356\left(\mathrm{M}^{+}, 18.1\right), 76$ (100). Anal. calcd. for $\mathrm{C}_{21} \mathrm{H}_{16} \mathrm{~N}_{4} \mathrm{O}_{2}$ : C, 70.77; $\mathrm{H}, 4.53 ; \mathrm{N}, 15.72$. Found: $\mathrm{C}, 75.50 ; \mathrm{H}, 5.43$; $\mathrm{N}, 8.40$.

\subsection{In-vitro anticancer screening}

\subsubsection{Animals, chemicals and facilities}

Ehrlich Ascites Carcinoma cells (EAC) were maintained in female Swiss albino mice weighing 25-30 g (the holding company for biological products and vaccines, VACSERA, Cairo, Egypt) were housed at a constant temperature $\left(24^{\circ} \mathrm{C}\right)$ with alternating $12 \mathrm{~h}$ light and dark cycles and fed standard laboratory food (Milad CO., Cairo, Egypt) and water ad libitum. All chemicals and reagents were of the highest grade commercially available. Facilities including animal house, biochemical equipments have been made available by the National Center for Radiation Research and Technology (NCRRT), Atomic Energy Authority (AEA), Cairo, Egypt. Animal care and handling was done according to the guidelines set by the world health organization, Geneva, Switzerland and approved from the committee for animals care at NCRRT.

\subsubsection{In-vitro anticancer activity using Ehrlich Ascites Carcinoma (EAC) cells}

Ehrlich Ascites Carcinoma cells (EAC) were obtained by needle aspiration of aseptic fluid from preinoculated mice; under aseptic conditions. Tumor cells suspension $\left(2.5 \times 10^{6}\right.$ per $\mathrm{mL}$ ) was prepared in RPMI-1640 media. Tested compounds were prepared with various dilutions by dissolving: $100,50,25$ and $10 \mathrm{mg}$ of the tested compounds in DMSO $(1 \mathrm{~mL})$. In a set of sterile test tubes $0.8 \mathrm{~mL}$ RPMI-1640 media containing (glutamine, fetal calf serum as nutrient, streptomycin and penicillin), $0.1 \mathrm{~mL}$ of each of the tested compounds (corresponding to 100, 50, 25 and $10 \mathrm{mg}$ ) were mixed then 0.1 $\mathrm{mL}$ of tumor cell suspension $\left(2 \times 10^{6}\right)$ was added. The test tubes were incubated at $37^{\circ} \mathrm{C}$ for $2 \mathrm{~h}$. Trypan blue exclusion test was carried out to calculate the percentage of non-viable cells after $2 \mathrm{~h}$ of incubation [17]. The total number of cells $/ \mathrm{mL}$ will be determined using the following calculations:
Cells $/ \mathrm{mL}=$ average cells count per 5 squares $\mathrm{x}$ dilution factor $\mathrm{x} 10^{4}$

Total cells $=$ cells $/ \mathrm{mL} \times$ the original volume of fluid from which the cell sample was removed

$\%$ cell non-viability $=$ total non-viable cells $($ stained) $/$ total cells $\times 100$

The results of in-vitro anticancer activity experiments are presented in (Table 1).

Table 1. In-vitro anticancer screening of the newly synthesized compounds against Ehrlich Ascites Carcinoma Tumor Cells (EAC).

\begin{tabular}{|c|c|c|c|c|c|c|}
\hline \multirow{3}{*}{ Compound No } & \multirow{2}{*}{\multicolumn{4}{|c|}{$\begin{array}{c}\text { Non-viable cells }(\%) \\
\text { Concentration }(\mu \mathrm{g} / \mathrm{mL})\end{array}$}} & \multirow{3}{*}{$\mathrm{IC}_{50}{ }^{\mathrm{a}}(\mu \mathrm{g} / \mathrm{mL})$} & \multirow{3}{*}{$\mathrm{IC}_{50} \mathrm{a}(\mu \mathrm{M}$} \\
\hline & & & & & & \\
\hline & 100 & 50 & 25 & 10 & & \\
\hline$\overline{4 a}$ & 100 & 50 & 25 & 10 & 25 & 62.34 \\
\hline $4 b$ & 100 & 50 & 25 & 10 & 50 & 119.9 \\
\hline $4 c$ & 100 & 60 & 40 & 10 & 46 & 106.48 \\
\hline $4 d$ & 60 & 75 & 50 & 20 & 25 & 57.87 \\
\hline $4 e$ & 100 & 90 & 70 & 10 & 45 & 104.4 \\
\hline 4f & 100 & 50 & 25 & 10 & 50 & 108.45 \\
\hline $4 \mathrm{~g}$ & 95 & 55 & 40 & 5 & 48 & 83.76 \\
\hline $4 \mathrm{~h}$ & 90 & 70 & 30 & 10 & 49 & 116.38 \\
\hline $4 \mathbf{i}$ & 95 & 60 & 30 & 10 & 49 & 105.15 \\
\hline $4 j$ & 95 & 65 & 20 & 5 & 47 & 119.59 \\
\hline $6 a$ & 95 & 80 & 60 & 10 & 23 & 58.52 \\
\hline $6 b$ & 50 & 10 & 0 & 0 & 100 & 244.5 \\
\hline $6 c$ & 100 & 100 & 60 & 30 & 15 & 36.67 \\
\hline $6 d$ & 100 & 60 & 40 & 5 & 46 & 108.49 \\
\hline $6 e$ & 100 & 90 & 50 & 20 & 25 & 58.96 \\
\hline $6 f$ & 100 & 70 & 40 & 10 & 43 & 91.68 \\
\hline $6 g$ & 100 & 50 & 25 & 10 & 50 & 121.06 \\
\hline $6 h$ & 100 & 60 & 30 & 5 & 48 & 107.14 \\
\hline 7 & 30 & 0 & 0 & 0 & $>100^{b}$ & - \\
\hline 8 & 20 & 0 & 0 & 0 & $>100^{b}$ & - \\
\hline 9 & 100 & 80 & 25 & 10 & 44 & 123.24 \\
\hline 10 & 100 & 90 & 60 & 30 & 21 & 58.98 \\
\hline Doxorubicin & 100 & 68 & 30 & 24 & 37 & 68.13 \\
\hline
\end{tabular}

a $\mathrm{IC}_{50}$ value: corresponds to the compound concentration causing $50 \%$ mortality in net cells.

${ }^{b}$ Compounds with $\mathrm{IC}_{50}>100 \mathrm{lg} / \mathrm{mL}$ are considered to be inactive.

\subsubsection{In-vitro anticancer activity using liver human tumor cell lines (HEPG2)}

The human tumor cell line (HEPG2) was available at the National Cancer Institute, Cairo, Egypt. Irradiation was performed in the National Cancer Institute, Cairo, Egypt using Gamma cell-40 $\left.{ }^{60} \mathrm{Co}\right)$ source. The anticancer activity of the newly synthesized compounds was mesured using the SulfoRhodamine-B stain (SRB) assay by the method of Skehan et al. [18]. Cells were plated in 96-multiwell plate $\left(10^{4}\right.$ cells/well) for $24 \mathrm{~h}$ before treatment with the compounds to allow attachment of cell to the wall of the plate. Tested compounds were dissolved in DMSO and diluted with saline to the appropriate volume. Different concentrations of the compounds under test $(5.0,12.5,25.0$ and $50.0 \mu \mathrm{M})$ were added to the cell monolayer. Triplicate wells were prepared for each individual dose. Monolayer cells were incubated with the compounds for $48 \mathrm{~h}$ at $37{ }^{\circ} \mathrm{C}$ and in atmosphere of $5 \% \mathrm{CO}_{2}$. After $48 \mathrm{~h}$, cells were fixed, washed and stained for $30 \mathrm{~min}$. with $0.4 \%$ (wt/vol) with SRB dissolved in $1 \%$ acetic acid. Unbounded dye was removed by four washes with $1 \%$ acetic acid, and attached stain was recovered with tris-EDTA buffer. Color intensity was measured in an ELISA reader. The relation between surviving fraction and drug concentration was plotted to get the survival curve of each tumor cell line after the specified time. The concentration required for $50 \%$ inhibition of cell viability (IC 50 ) was calculated and compared with the reference drug doxorubicin and the results are given in Table 2. 
Table 2. In-vitro anticancer evaluation of compounds $\mathbf{4 a}, \mathbf{4 d}, \mathbf{6 a}, \mathbf{6 c}, \mathbf{6 e}$ and 10 against human liver cell line (HEPG2).

\begin{tabular}{|c|c|c|c|c|c|}
\hline \multirow{3}{*}{ Compound No } & \multicolumn{4}{|c|}{ Compound concentration $(\mu \mathrm{M})$} & \multirow[b]{2}{*}{$\mathrm{IC}_{50}(\mu \mathrm{M})$} \\
\hline & 5.0 & 12.5 & 25.0 & 50.0 & \\
\hline & \multicolumn{4}{|c|}{ Surviving fraction (mean $\pm \mathrm{SE}$ ) } & \\
\hline Doxorubicin & $0.921 \pm 0.020$ & $0.846 \pm 0.020$ & $0.761 \pm 0.010$ & $0.494 \pm 0.030$ & 38.46 \\
\hline $4 a$ & $0.845 \pm 0.002$ & $0.724 \pm 0.009$ & $0.576 \pm 0.028$ & $0.376 \pm 0.047$ & 31.2 \\
\hline 4d & $0.623 \pm 0.018$ & $0.523 \pm 0.031$ & $0.367 \pm 0.022$ & $0.271 \pm 0.012$ & 11.7 \\
\hline $6 a$ & $0.723 \pm 0.012$ & $0.635 \pm 0.041$ & $0.523 \pm 0.047$ & $0.244 \pm 0.022$ & 21.81 \\
\hline $6 c$ & $0.922 \pm 0.064$ & $0.744 \pm 0.014$ & $0.630 \pm 0.016$ & $0.436 \pm 0.012$ & 38.9 \\
\hline $6 e$ & $0.876 \pm 0.064$ & $0.744 \pm 0.014$ & $0.509 \pm 0.016$ & $0.312 \pm 0.012$ & 25.83 \\
\hline 10 & $0.910 \pm 0.064$ & $0.789 \pm 0.014$ & $0.598 \pm 0.016$ & $0.309 \pm 0.012$ & 32.2 \\
\hline
\end{tabular}

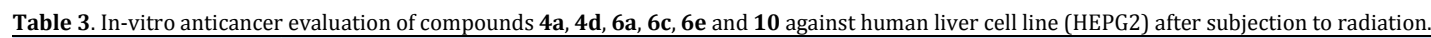

\begin{tabular}{|c|c|c|c|c|c|}
\hline \multirow[t]{2}{*}{ Compound No } & \multicolumn{4}{|c|}{$\begin{array}{l}\text { Compound concentration }(\mu \mathrm{M})+\text { irradiation }(8 \mathrm{~Gy}) \\
\text { Surviving fraction }(\text { mean } \pm S E) \text { a }\end{array}$} & \multirow[t]{2}{*}{$\mathrm{IC}_{50}(\mu \mathrm{M})$} \\
\hline & 5.0 & 12.5 & 25.0 & 50.0 & \\
\hline $4 \mathbf{4 a}$ & $0.587 \pm 0.01$ & $0.376 \pm 0.02$ & $0.329 \pm 0.05$ & $0.198 \pm 0.06$ & 5.03 \\
\hline 4d & $0.487 \pm 0.07$ & $0.398 \pm 0.01$ & $0.198 \pm 0.01$ & $0.100 \pm 0.08$ & 6.37 \\
\hline $6 a$ & $0.355 \pm 0.01$ & $0.276 \pm 0.01$ & $0.245 \pm 0.01$ & $0.187 \pm 0.07$ & 2.68 \\
\hline $6 c$ & $0.535 \pm 0.04$ & $0.498 \pm 0.01$ & $0.287 \pm 0.01$ & $0.198 \pm 0.06$ & 8.38 \\
\hline $6 e$ & $0.589 \pm 0.04$ & $0.234 \pm 0.01$ & $0.218 \pm 0.01$ & $0.156 \pm 0.06$ & 6.04 \\
\hline 10 & $0.398 \pm 0.04$ & $0.212 \pm 0.01$ & $0.200 \pm 0.01$ & $0.189 \pm 0.06$ & 3.35 \\
\hline
\end{tabular}

a Each value is the mean of three experiments \pm standard error.

\subsection{Radiosensitizing evaluation}

The most potent compounds resulted from the in vitro anticancer screening; compounds $4 \mathbf{a}, \mathbf{4 d}, \mathbf{6 a}, \mathbf{6 c}, \mathbf{6 e}$ and 10, were selected to be evaluated again for their in vitro anticancer activity alone and in combination with $\gamma$-radiation. This study was conducted to evaluate the ability of these compounds to enhance the cell killing effect of $\gamma$-radiation. Cells were subjected to a single dose of $\gamma$-radiation at a dose level of 8 Gy with a dose rate of $2 \mathrm{~Gy} / \mathrm{min}$. Irradition was performed in the National Cancer Institute, Cairo University, using Gamma cell$40\left({ }^{60} \mathrm{Co}\right)$ source. The surviving fractions were expressed as means \pm standard error. The results were given in Table 3 .

\section{Results and discussion}

\subsection{Chemistry}

Schemes 1 and 2 outline the synthetic pathway used to obtain 1,6-dihydropyridines (4a-j), 1,2-dihydroisoquinolines (6a-h), 2H-chromenes (7 and 8) and $3 H$-chromeno[3,4c]pyridines (9 and 10). The starting material, 3-cyano- $N$-(3ethylphenyl) acetamide, 3, was prepared via reaction of 3ethylaniline $\mathbf{1}$ with ethyl cyanoacetate $\mathbf{2}$. Compound $\mathbf{3}$ was confirmed by elemental analysis, IR, ${ }^{1} \mathrm{H}$ NMR and mass spectral data (Scheme 1). Upon treatment of compound $\mathbf{3}$ with required aldehyde and ethyl cyanoacetate in the presence of catalytic amount of piperidine furnished ethyl 4-substituted-2-amino-5cyano-1-(3-ethylphenyl)-6-oxo-1,6-dihydropyridine-3-

carboxylate, $\mathbf{4 a - j}$. The structure of compounds $\mathbf{4 a - j}$ was deduced from elemental analyses and spectral data (Scheme 1). Cycloaddition occurred upon treatment of compound $\mathbf{3}$ with acetylacetone to furnish 2-pyridone derivative $\mathbf{5}$ which upon reaction with the corresponding arylidinemalononitriles yielded the correspondingisoquinoline derivatives $\mathbf{6 a - h}$ (Scheme 2).

Furthermore, Perkin reaction was carried when compound 3 was reacted with salicyaldehyde in the presence ofacetic anhydride containing sodium acetate to give the corresponding 2 -oxochromene derivative $\mathbf{7}$, while reaction of compound $\mathbf{3}$ with saliclyaldehyde in ammonium acetate furnished 2iminochromene 8. The structure of compound $\mathbf{7}$ and $\mathbf{8}$ was supported in the basis of elemental analyses, IR, ${ }^{1} \mathrm{H}$ NMR and mass spectral data. The chromene derivative $\mathbf{7}$ and $\mathbf{8}$ were further reacted with malononitrile in the presence of ammonium acetate to give the corresponding chromeno pyridine derivatives 9 and 10, respectively (Scheme 3). The structure of compounds $\mathbf{9}$ and $\mathbf{1 0}$ was elucidated from elemental analyses and spectral data.

\subsection{In-vitro anticancer screening}

\subsubsection{In-vitro anticancer activity using Ehrlich Ascites Carcinoma (EAC) cells}

Doxorubicin, the reference drug used in this study is one of the most effective antitumor agents used to produce regressions in acute leukemia's, Hodgkin's disease, and other lymphomas. The relationship between survival ratio and drug concentration was plotted to obtain the survival curve of Ehrlich Ascites Carcinoma (EAC) cells and human liver cell line (HEPG2). The response parameter calculated was $\mathrm{IC}_{50}$ value (Tables 1 and 2), which corresponds to the compound concentration causing $50 \%$ mortality in net cells.

\subsubsection{Structure Activity Relationship (SAR)}

The cytotoxicity of twenty-two compounds was examined on Ehrlich Ascites Carcinoma (EAC) cells. It is clear from the results in (Table 1) that in the series of 1,6-dihydropyridine $\mathbf{4 a -}$ $\mathbf{j}$, the most potent in this series is the 4-methyl derivative $\mathbf{4 a}$ $\left(\mathrm{IC}_{50}=62.34 \mu \mathrm{M}\right)$ which was found to be more potent than the reference drug $\left(\mathrm{IC}_{50}=68.13 \mu \mathrm{M}\right)$ and also more potent than the corresponding 4-methoxy derivative $\mathbf{4 b}\left(\mathrm{IC}_{50}=119.9 \mu \mathrm{M}\right)$ and the 3-ethoxy-4-methoxy derivative $\mathbf{4 f}\left(\mathrm{IC}_{50}=108.45 \mu \mathrm{M}\right)$ and is nearly as potent as the trimethoxy derivative $\mathbf{4 g}\left(\mathrm{IC}_{50}=83.76\right.$ $\mu \mathrm{M})$. On the other hand, the 4-nitro derivative $\mathbf{4 d}\left(\mathrm{IC}_{50}=57.87\right.$ $\mu \mathrm{M})$ was found to be more potent than the corresponding 3-nitro derivative $4 \mathbf{c}\left(\mathrm{IC}_{50}=106.48 \mu \mathrm{M}\right)$, finally, the least potent in this series was the halogenated derivatives $4 \mathbf{h}$ and $\mathbf{4 i}\left(\mathrm{IC}_{50}=\right.$ 116.38 and $105.15 \mu \mathrm{M})$. Concerning the series of 1,2 dihydroisoquinoline $\mathbf{6 a - h}$, the most potent in this series is the 4-methoxy derivative $\mathbf{6 c}\left(\mathrm{IC}_{50}=36.67 \mu \mathrm{M}\right)$ which was found to be more potent than the reference drug $\left(\mathrm{IC}_{50}=68.13 \mu \mathrm{M}\right)$ and the corresponding 4-methyl derivative $6 \mathbf{a}\left(\mathrm{IC}_{50}=58.52 \mu \mathrm{M}\right)$, the trimethoxy derivative $6 \mathbf{6}\left(\mathrm{IC}_{50}=91.68 \mu \mathrm{M}\right)$ and the 2-methoxy derivative $6 \mathbf{b}\left(\mathrm{IC}_{50}=244.5 \mu \mathrm{M}\right)$ which is the least potent in this series. On the other hand, the 4-nitro derivative $6 \mathbf{e}\left(\mathrm{IC}_{50}=58.96\right.$ $\mu \mathrm{M})$ was found to be more potent than the corresponding 3-nitro derivative $\mathbf{6 d}\left(\mathrm{IC}_{50}=108.49 \mu \mathrm{M}\right)$, while, the chloro derivatives $\mathbf{6 g}$ and $\mathbf{6 h}$ showed nearly equipotent activity $\left(\mathrm{IC}_{50}=\right.$ 121.06 and $107.14 \mu \mathrm{M}$ ). Finally, the chromeno[3,4-c]pyridone derivatives 9 and $10\left(\mathrm{IC}_{50}=123.24\right.$ and $\left.58.98 \mu \mathrm{M}\right)$ showed more potent activity than the corresponding chromene derivatives $\mathbf{7}$ and $\mathbf{8}$ which showed no $\mathrm{IC}_{50}$. 


\subsubsection{In-vitro anticancer activity using liver human tumor cell lines (HEPG2)}

This study was performed to evaluate the cytotoxic activity of the most potent six compounds resulted from EAC assay (compounds 4a, 4d, 6a, 6c, 6e and 10). We can conclude from the results obtained from (Table 2) that indeed these compounds showed potent activity on HEPG2 cell line. The most potent was the 4-nitro dihydropyridone derivative 4d $\left(\mathrm{IC}_{50}=11.7 \mu \mathrm{M}\right)$ which is more potent than doxorubicin $\left(\mathrm{IC}_{50}=\right.$ $38.46 \mu \mathrm{M}$ ), while, the increasing order of the rest of the compounds was as follows: 4-methyl isoquinoline derivative $\mathbf{6 a}$ $\left(\mathrm{IC}_{50}=21.81 \mu \mathrm{M}\right)$, the 4-nitro isoquinoline derivative $\mathbf{6 e}\left(\mathrm{IC}_{50}=\right.$ $25.83 \mu \mathrm{M})$, the 4-methyl dihydropyridone derivative $4 \mathbf{a}\left(\mathrm{IC}_{50}=\right.$ $31.2 \mu \mathrm{M})$, the chromeno[3,4-c]pyridine $\mathbf{1 0}\left(\mathrm{IC}_{50}=32.2 \mu \mathrm{M}\right)$ and the 4-methoxy isoquinoline $6 \mathrm{c}\left(\mathrm{IC}_{50}=38.9 \mu \mathrm{M}\right)$.

\subsection{Radiosensitizing evaluation}

The rationale for combining chemotherapy and radiotherapy is based mainly on two ideas, one being spatial cooperation, which is effective if chemotherapy is sufficient to eradicate subclinical metastases and if the primary local tumor is effectively treated by radiotherapy. In this regard, no interaction between radiotherapy and chemotherapy is required. The other idea is the enhancement of radiation effects. Cytotoxic agents can enhance radiation effects by direct enhancement of the initial radiation damage by incorporating drugs into DNA, inhibiting cellular repair, accumulating cells in a radiosensitive phase or eliminating radioresistant phase cells, eliminating hypoxic cells or inhibiting the accelerated repopulation of tumor cells [17]. Consequently, the ability of the most six active compounds $4 \mathbf{a}, 4 \mathbf{d}, \mathbf{6 a}, \mathbf{6 c}, \mathbf{6 e}$ and 10, to enhance the cell killing effect of $\gamma$-irradiation was studied. From the results obtained in (Table 2), compound 4a showed an in vitro cytotoxic activity with IC 50 value of $31.2 \mu \mathrm{M}$, when the cells were subjected to different concentrations of the compound alone. While, when the cells were subjected to the same concentrations of compound $\mathbf{4 a}$, and irradiated with a single dose of $\gamma$-radiation at a dose level of $8 \mathrm{~Gy}$, as shown in (Table 3 ), the $\mathrm{IC}_{50}$ value was synergistically decreased to 5.03 $\mu \mathrm{M}$. Similarly, compounds $\mathbf{4 d}, \mathbf{6 a}, \mathbf{6 c}, \mathbf{6 e}$ and 10 showed IC 50 values of $11.7,21.81,38.9,25.83$ and $32.2 \mu \mathrm{M}$, respectively, when used alone, as shown in (Table 2). The $\mathrm{IC}_{50}$ value was decreased to $6.37,2.68,8.38,6.04$ and $3.35 \mu \mathrm{M}$, respectively, when the cells were treated with compounds $\mathbf{4 d}, \mathbf{6 a}, \mathbf{6 c}, \mathbf{6 e}$, and $\mathbf{1 0}$ in combination with $\gamma$-radiation. From these results, we can conclude that the combination of compounds $4 a, 4 d, 6 \mathbf{a}, \mathbf{6 c}$, 6e and 10 and ionizing radiation synergistically enhanced growth inhibition on liver cancer cells, compared with each agent alone.

\section{Conclusion}

We report in this work the synthesis of new 2-pyridone, isoquinoline, chromene and chromenopyridone derivatives. It was clearly observed from the results of in-vitro cytotoxic screening that some of the synthesized compounds exhibited significant anticancer activity on Ehrlich Ascites Carcinoma (EAC) and human liver tumor cell line (HEPG2). While, combining these compounds with radiation at the same concentrations enhances their activity which demonstrates the importance of the combination therapy for the patients with cancer to decrease the side effects of both drugs and radiation.

\section{Acknowledgements}

The authors are grateful to the sponsorship of the Research Center, College of Pharmacy and the Deanship of Scientific Research, King Saud University, Riyadh, Saudi Arabia.

\section{References}

[1]. Abadi, A. H.; Ibrahim, T. M.; Abouzid, K. M.; Lehmann. J.; Tinsley, H. N.; Gary, B. D.; Piazza, G. A. Bioorg. Med. Chem. 2009, 17, 5974-5982.

[2]. Cheney, I. W.; Yan, S.; Appleby, T.; Walker, H.; Vo, T.; Yao, N. Hamatake, R.; Hong, Z.; Wu, J. Z. Bioorg. Med. Chem. Lett. 2007, 17, 1679-1683.

[3]. Wendt, M. D.; Sun, C.; Kunzer, A.; Sauer, D.; Sarris, K.; Hoff, E.; Yu, L.; Nettesheim, D. G.; Chen, J.; Jin, S.; Comess, K. M.; Fan, Y.; Anderson, S. N.; Isaac, B.; Olejniczak, E. T.; Hajduk, P. J.; Rosenberg, S. H.; Elmore, S. W. Bioorg. Med. Chem. Lett. 2007, 17, 3122-3129.

[4]. Aqui, N. A.; Vonderheide, R. H. Cancer Biol. Ther. 2008, 7, 1888-1889.

[5]. Ambrosini, G.; Adida, C.; Altieri, D. C. Nat. Med. 1997, 3, 917-921.

[6]. Gary, P.; Soh, J. W.; Mao, Y.; Kim, M. G.; Pamukcu, R.; Li, H.; Piazza, G. A. Thompson, W. J.; Weinstein, I. B. Clin. Cancer Res. 2000, 6, 4136-4141.

[7]. Alagille, D.; Baldwin, R. M.; Tamagnan, G. D. Tetrahedron Lett. 2004, 45, 6179-6181.

[8]. Raj, T.; Bhatia, R. K.; Kapur, A.; Sharma, M.; Saxena, A. K.; Ishar, M. P. S. Eur. J. Med. Chem. 2010, 45, 790-794.

[9]. Endo, S.; Matsunaga, T.; Kuwata, K.; Zhao, H. T.; El-Kabbani, O.; Kitade, Y.; Hara, A. Bioorg. Med. Chem. 2010, 18, 2485-2490.

[10]. Sabry, N. M.; Mohamed, H. M.; Shawky, E.; Khattab, A. E. H.; Motlaq, S. S.; El-Agrody, A. M. Eur. J. Med. Chem. 2011, 46, 765-772.

[11]. Ghorab, M. M.; Ragab, F. A.; Hamed, M. M. Eur. J. Med. Chem. 2009, 44, 4211-4217.

[12]. Al-Said, M. S.; Ghorab, M. M.; Al-Qasoumi, S. I.; El-Hossary, E. M Noaman, E. Eur. J. Med. Chem. 2010, 45, 3011-3018.

[13]. Al-Qasoumi, S. I.; Al-Taweel, A. M.; Alafeey, A. M.; Ghorab, M. M.; Noaman, E. Bioorg. Med. Chem. Lett. 2009, 19, 6939-6942.

[14]. Ghorab, M. M.; Ragab, F. A.; Al-Qasoumi, S. I.; Alafeefy, A. M. Aboulmagd, S. A. Eur. J. Med. Chem. 2010, 45, 171-178.

[15]. Al-Qasoumi, S. I.; Al-Taweel, A. M.; Al-Afeefy, A. M.; Noaman, E.; Ghorab, M. M. Eur. J. Med. Chem. 2010, 45, 738-744.

[16]. Al-Qasoumi, S. I.; Al-Taweel, A. M.; Alafeefy, A. M.; Ghorab, M. M.; Noaman, E. Eur. J. Med. Chem. 2010, 45, 1849-1853.

[17]. Devi, P. U.; Solomon, F. E.; Sharada, A. C. Pharm. Biol. 1999, 37(3), 231236.

[18]. Skehan, P.; Storeng, R.; Scudiero, D.; Monks, A.; McMahon, J.; Vistica, D.; Warren, J. T.; Bokesch, H.; Kenney, S.; Boyd, M. R. J. Natl. Cancer Inst. 1990, 82, 1107-1112.

[19]. Nishimura, Y. Int. J. Clin. Oncol. 2004, 9, 414-420. 